\title{
Teoría general del delito \\ DE MANUEL VIDAURRI ARÉCHIGA, OXFORD UNIVERSITY PRESS, MÉXICO, 2013
}

José Pablo VEGA AYALA

La ciencia del Derecho penal se encuentra conformada por múltiples materias que pretenden solucionar las interrogantes esenciales que presenta el por antonomasia complejo Derecho penal y con ello atender a la finalidad práctica que persigue el quehacer científico producto de la realización que se hace de la interpretación de la ley penal. Uno de los grandes apartados que venimos comentando es el que realiza en esta ocasión el profesor Doctor Manuel Vidaurri², centrando su actividad investigadora en su nueva obra intitulada "Teoría general del delito". Un libro que concentra los temas de raigambre que han preocupado a la dogmática jurídico - penal y temas novedosos como la inclusión de la teoría del caso en el nuevo sistema acusatorio, por mencionar alguno. Una obra que viene a demostrar la vasta experiencia y dominio del tema que caracteriza a su autor, reflejo de la actividad cotidiana, interés y dedicación con su disciplina de estudio.

Quienes consulten la obra, encontraran toda la información necesaria desde las perspectivas doctrinaria, legislativa, jurisprudencial, para reforzar lo anterior contempla una serie de casos prácticos y actividades que sugiere el autor para lograr el cabal entendimiento y comprensión de los elementos teóricos desarrollados.

La teoría del delito para ser estudiada de acuerdo con nuestro sistema jurídico penal de corte romano - germánico, analiza los elementos del delito en sus vertientes positiva y negativa, es precisamente en esta obra donde se desglosan hasta los últimos pormenores de los elementos estructurales del delito que son la acción, la tipicidad, la antijuridicidad y la culpabilidad.

Bajo esta tesitura, expondremos en breves líneas, algunos de los temas desarrollados y explicados por el autor con gran claridad y concreción a lo largo del texto ${ }^{3}$. En los primeros capítulos, el autor desarrolla el sentido, los alcances y el método de la dogmática jurídico penal; estableciendo las premisas y los conceptos en torno a los cuales se desarrolla la teoría general del delito. Nos presenta un breve repaso histórico de las sistemáticas de la teoría del delito, pasando lista por la escuela clásica, el casualismo valorativo, el finalismo y el funcio-

\footnotetext{
${ }^{1}$ Estudiante del Departamento de Derecho de la División de Derecho Política y Gobierno de la Universidad de Guanajuato.

${ }^{2}$ Doctor en Derecho por la Universidad de Sevilla. Profesor Investigador del Departamento de Derecho de la División de Derecho, Política y Gobierno de la Universidad de Guanajuato. Pertenece al Sistema Nacional de Investigadores (Nivel II) y cuenta con el perfil PROMEP. Miembro del Cuerpo Académico: Ciencia Penal, Estado de Derecho y Derechos Humanos.

3 VIDAURRI ARÉCHIGA, Manuel, Teoría general del delito, Oxford University Press, Mexico, 2013.
} 
nalismo con todos sus modelos sistemáticos que presentan. Con esto nos proporciona un panorama general de los elementos del delito y una referencia conveniente para el análisis de los subsecuentes capítulos.

De esta manera el Doctor Vidaurri empieza desarrollando la teoría de la acción, su concepto y evolución a la luz de las diversas sistemáticas. En contrapartida encontramos la omisión en derecho penal, las clases de omisión y los problemas que presenta dicha categoría en la teoría del delito. En capítulo especial nos desarrolla el tema de la imputación objetiva del resultado que eventualmente permite atribuir la responsabilidad a una persona determinada por el resultado de su acción, siempre y cuando se acredite, el nexo causal entre la acción y el resultado concreto; actividad que no siempre resulta sencilla.

Para el estudio de la tipicidad en sus aspectos positivo y negativo, por ser un elemento que cumple funciones muy importantes nos señala que: por un lado, es una categoría que garantiza el principio de legalidad porque solo valiéndonos de una formula general es posible subsumir todas las conductas con las características esenciales a la descripción que encontramos en la ley penal, y por el otro, la tipicidad nos sirve de referencia o indicio para los subsecuentes eslabones conformantes del delito. Apartado en que el autor, con evidente vinculación, va desmenuzando lo referente a las funciones, estructura, elementos y clases de tipos penales. Incorpora también el estudio referente a los tipos dolosos e imprudentes, el error de tipo y el caso fortuito.

Semejante actividad es la que presenta al momento de analizar la antijuridicidad en sus aspectos generales, proporcionando una explicación pormenorizada y completa respecto de las causas de exclusión de la antijuridicidad, a saber: la legitima defensa, el cumplimiento de un deber, el ejercicio legítimo de un derecho, el estado de necesidad y el consentimiento como causas de justificación.

Para el tratamiento de la categoría dogmática de la culpabilidad, el autor nos presenta un estudio profundo que comprende la evolución dogmática de la culpabilidad, las teorías clásicas - por llamarlas de algún modo - que se han ocupado sobre este aspecto; así como de otras teorías más próximas a nuestro tiempo, producto de un Derecho penal moderno que interactúa con otras disciplinas científicas. Nos explica a detalle los elementos que configuran la culpabilidad a la luz de la teoría finalista en apartados especiales y que son: a) la imputabilidad (en sus aspectos positivo y negativo), b) el conocimiento de la antijuridicidad del hecho realizado, y c) la exigibilidad de un comportamiento distinto.

En el desarrollo de la institución de la tentativa de cometer el delito nos expone los elementos propios de la misma y a partir de su definición el desarrollo de sus elementos, tipos de tentativa, el desistimiento de cometer el delito y el fundamento sancionador de la tentativa.

Interesantes comentarios son los que nos proporciona al momento de explicar lo referente a la autoría y participación, incluyendo en este apartado las consideraciones generales de la tentativa, lo referente a la teoría del dominio del hecho con todas sus implicaciones y elucubraciones teóricas; para el tratamiento de la participación contempla su concepto, el fundamento de su castigo, las modalidades de participación y la figura del encubrimiento.

Reflexiones de gran utilidad y concreción son las que vierte respecto al tema del concurso de delitos y de leyes, donde el autor enfatiza en las diferencias entre uno y otro tipo de concursos en miras de comprensión didáctica meramente.

El libro en comento es un libro de vanguardia, ya que incorpora temas de gran novedad, producto de la reforma constitucional del 18 de junio de 2008 que vino a implementar el 
sistema de justicia penal de tipo acusatorio; el Doctor Vidaurri trata de manera especial en un capítulo dedicado a la teoría del delito y el relevante papel que viene a desempeñar en el nuevo sistema acusatorio, a diferencia de lo que piensan algunos que pretenden dar preminencia al terreno procesal y desprestigio a la dogmática penal. ${ }^{4}$ El manejo y conocimiento de la dogmática jurídico penal viene a servir ahora más que nunca en la construcción adecuada de la denominada teoría del caso, de esta manera el estudio de la teoría general del delito seguirá fungiendo como herramienta imprescindible y de gran utilidad práctica para explicar los hechos jurídicamente, desentrañar el alcance y sentido de las instituciones penales. En palabras del autor, la dogmática penal, en tanto gramática de lo jurídico-penal, permite precisamente no solo establecer ese dialogo entre las partes del proceso sino que, además, fundamenta la decisión judicial. ${ }^{5}$

Finalmente, la obra concluye con algunas orientaciones y lineamientos que nos ayudan a resolver casos de teoría del delito, configuran una apreciable herramienta para la solución de casos penales, que valiéndonos de una adecuada metodología permiten facilitarnos el análisis, comprensión y resolución de casos prácticos.

Así pues, la obra escrita por el jurista Manuel Vidaurri representa una aportación de incuestionable calidad y utilidad que constituye sin lugar a dudas una extraordinaria herramienta de referencia desarrollada en veintidós capítulos, sobre la Teoría General del Delito; todos ellos dirigidos a nosotros (los estudiantes de los primeros cursos de Derecho penal). Sin duda un instrumento de consulta imprescindible para los estudiantes y profesionales del derecho.

4 Un planteamiento en este sentido lo desarrolla Javier Dondé Matute en: "Critica a la teoría del delito: bases para su destrucción”, en Revista Defensa Penal, México, mayo 2010.

5 Vid. Manuel Vidaurri Aréchiga, "Una recapitulación entorno a la dogmática penal, teoría del delito y teoría del caso” en Revista Letras Jurídicas, número 12, México, primavera de 2011. 
